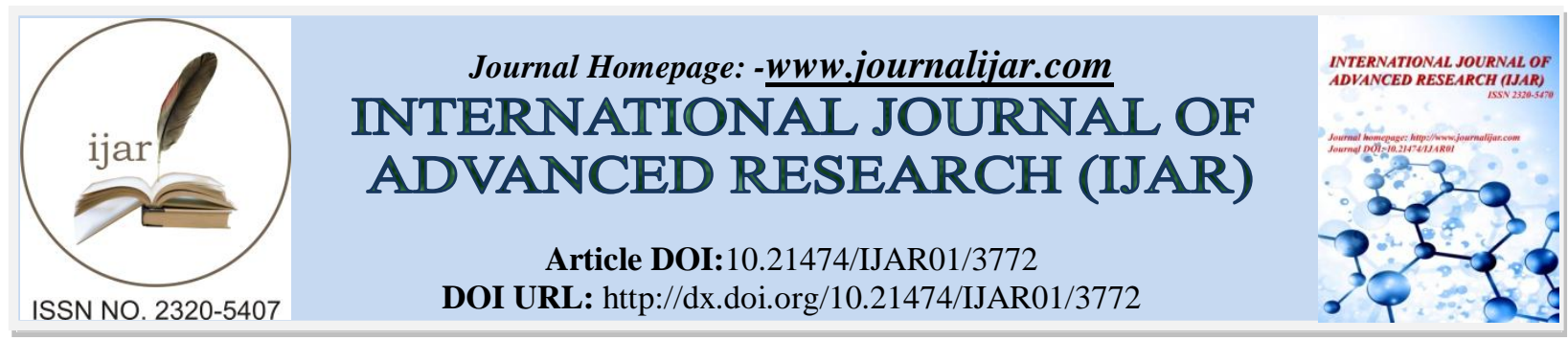

RESEARCH ARTICLE

\title{
STUDIES ON PRE-GERMINATION SEED TREATMENT OF A TRADITIONAL MEDICINAL PLANT -MADHUCA LONGIFOLIAL.
}

\section{Dr. R. Karthiyayini*}

Assistant Professor, Department of Botany, Avinashilingam Institute for Home Science and Higher Education for Women, Coimbatore-641043, Tamilnadu, India.

\section{Manuscript Info}

Manuscript History

Received: 17 January 2017

Final Accepted: 08 February 2017

Published: March 2017

Key words:-

Madhuca longifolia, pre-sowing

treatment, seedling growth.

\begin{abstract}
Madhuca longifolia L ( Family : Sapotaceae)is a medicinal and economic important tree. This study was carried out to know the effect of pretreatment on seed germination and seedling growth parameters of size graded $M$. longifolia seeds viz. large, medium and small. The result shows that the large and medium sized seeds treat with tap water is significantly increased the germination and seedling growth compared to control and other treatments.
\end{abstract}

Copy Right, IJAR, 2017,. All rights reserved.

\section{Introduction:-}

To achieve success in any plantation programs a good start is essential from the germination stage.In order to that, many tree species germinate readily when subjected to favorable conditions of moisture, gaseous balance, light and temperature, but many other species possess degree of seed dormancy or have other germination problems. In order to ensure quick and even germination in nursery beds, artificial treatments to be attempted before sowing (Hanumantha et al., 2002). Trees have been considered as vital part of the life and their significance being described in epics. Many traditional societies all over the world value a large number of plant species for a wide variety of reasons viz., food, fibre, shelter, medicine, etc..

Madhuca longifolia L. is a commonly known as Mahua, or Butter nut tree. It is a medium sized deciduous tree distributed in Nepal, India and Srilanka (Saluja et al., 2011). M. longifolia seeds are of economic importance as they are good source of edible fats (Chatterjee and Pakrashi 2000). The medicinal properties attributed to this plant are stimulant, demulcent, emollient, heating and astringent (Awashti and Mitra 1967).The flowers have been traditionally used as cooling agent, tonic, aphrodisiac, and astringent, demulcent and for the treatment of chronic tonsillitis (Chandra 2001). The leaves are expectorant and also used for chronic bronchitis. The bark is used for rheumatism (Sunita and Sorojini, 2013). The root powder is used to cure diarrhea and other chronic fluxes (Chatterjee and Pakrashi 2000).

Since the present study was carried out to find out the effectiveness of size graded seeds in various pretreatment methods to understand the behavior of seed germination and seedling growth which will reduce the maintenance cost in nursery and result in good crop-stand.

\section{Materials and Method:-}

The freshly collected seeds of $M$. longifolia were sorted out into three groups namely large, medium and small on the bases of visual observation. The following treatments was given to the seeds 
T0: Control (non-treated)

$\mathrm{T} 1$ : Seeds were soaked in warm water $\left(50-55^{\circ} \mathrm{C}\right)$ for 10 minutes,

$\mathrm{T} 2$ : Seeds were soaked in warm water $\left(50-55^{\circ} \mathrm{C}\right)$ for 15 minutes,

T3: Seeds were placed under running tap water for 12 hours,

T4: Seeds were placed under running tap water for 24 hours,

T5: Seeds were soaked in concentrated sulfuric acid for 10 minutes,

T6: Seeds were soaked in concentrated sulfuric acid for 20 minutes,

T7: Seeds were soaked in concentrated sulfuric acid for 1 hour,

T8: Seeds were soaked in concentrated nitric acid for 10 minutes,

T9: Seeds were soaked in concentrated nitric acid for 20 minutes,

T10: Seeds were soaked in concentrated nitric acid for 1 hour,

T11: Seeds were manually by rubbing on sand paper at the cotyledon ends,

T12: A small piece of seed coat was removed mechanically using razor blade.

After pretreatment by various methods (T1- T10), the seeds were thoroughly washed in tap water and were sown in $30 \mathrm{~cm} \mathrm{X} 11 \mathrm{~cm}$ polythene bags containing sand medium kept at room temperature $\left(28+2^{0} \mathrm{C}\right)$. The germination studies were carried out with five replicates and each replication consisted of fifty seeds of uniform size. The mechanically scarified (T11 and T12) seeds are sown immediately. Watering was done daily and germination was recorded on alternate days during 90 day period for experimentation. The statistical analysis was done by the method of Duncan's Multiple Range Test (DMRT).

\section{Result and Discussion}

In M. longifolia, large sized seeds treated with tap water (24 hours) were enhanced the higher percentage of germination when compared to other treatments. Whereas the medium and small sized seeds exhibited poor germination in all the treatments (Fig. 1). The continuous soaking of seeds in running tap water will leaches out inhibitory chemicals, thereby improving the germination of chemically dormant seeds ( Bewley and Black 1994). The root and shoot length of large sized seeds exhibited more in 12 hours tap water treated seedlings followed by 24 hours treatment compared to control ( Fig. 2 \& 3). Mean number of days taken for germination of the seedlings was also less for large and medium sized seeds than the small size.

In the present study large sized seeds of $M$. longifolia treated with tap water for $48 \mathrm{hrs}$ showed higher percentage of germination and seedling growth. This study is concordant to Naidu and Mastan (2001) in Pterocarpus santilinus. They observed that the seeds kept under running tap continuously for 6 days exhibits more germination. 
Fig -1: Effect of pretreatment on seede germination of size greated seeds of $M$. longifolia

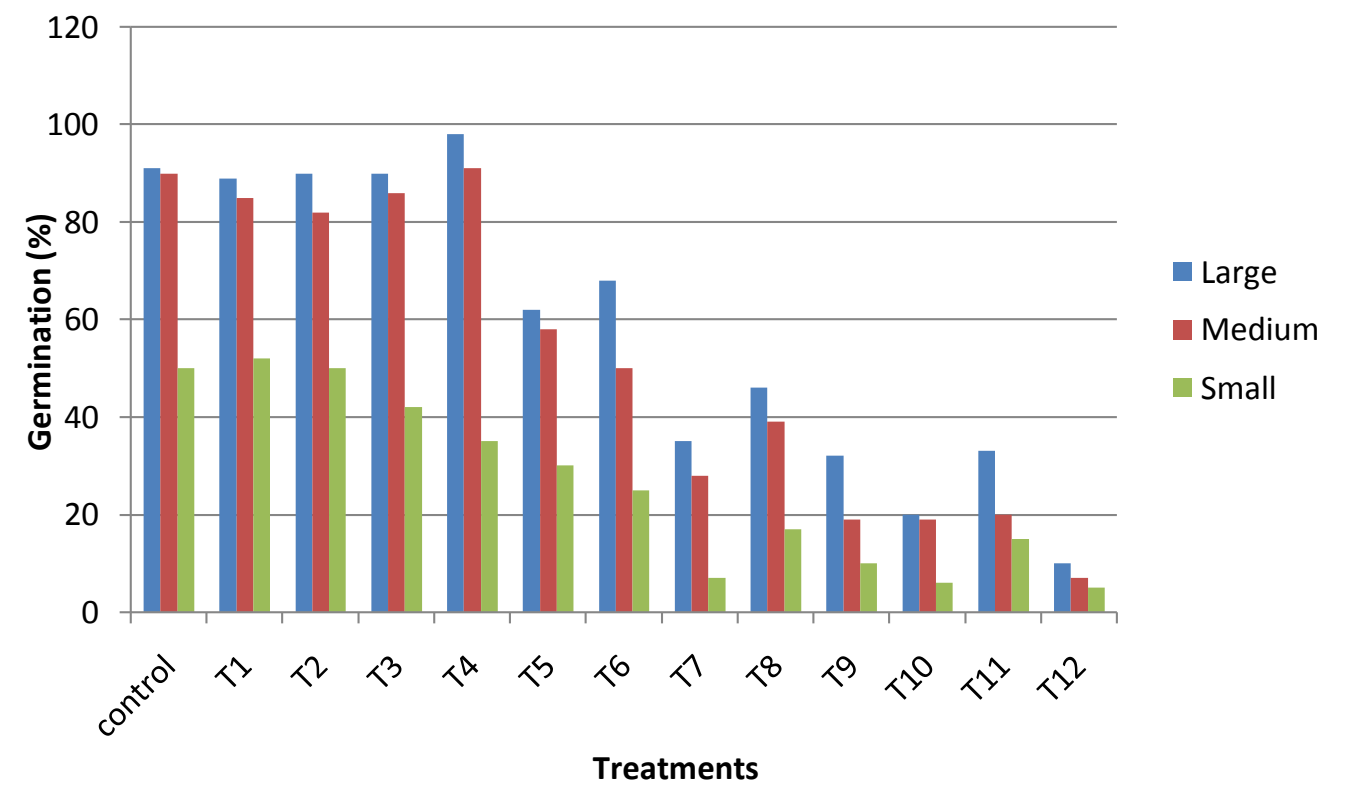

Fig -2: Effect of pretreatment on root length of size greated seeds of M.longifolia

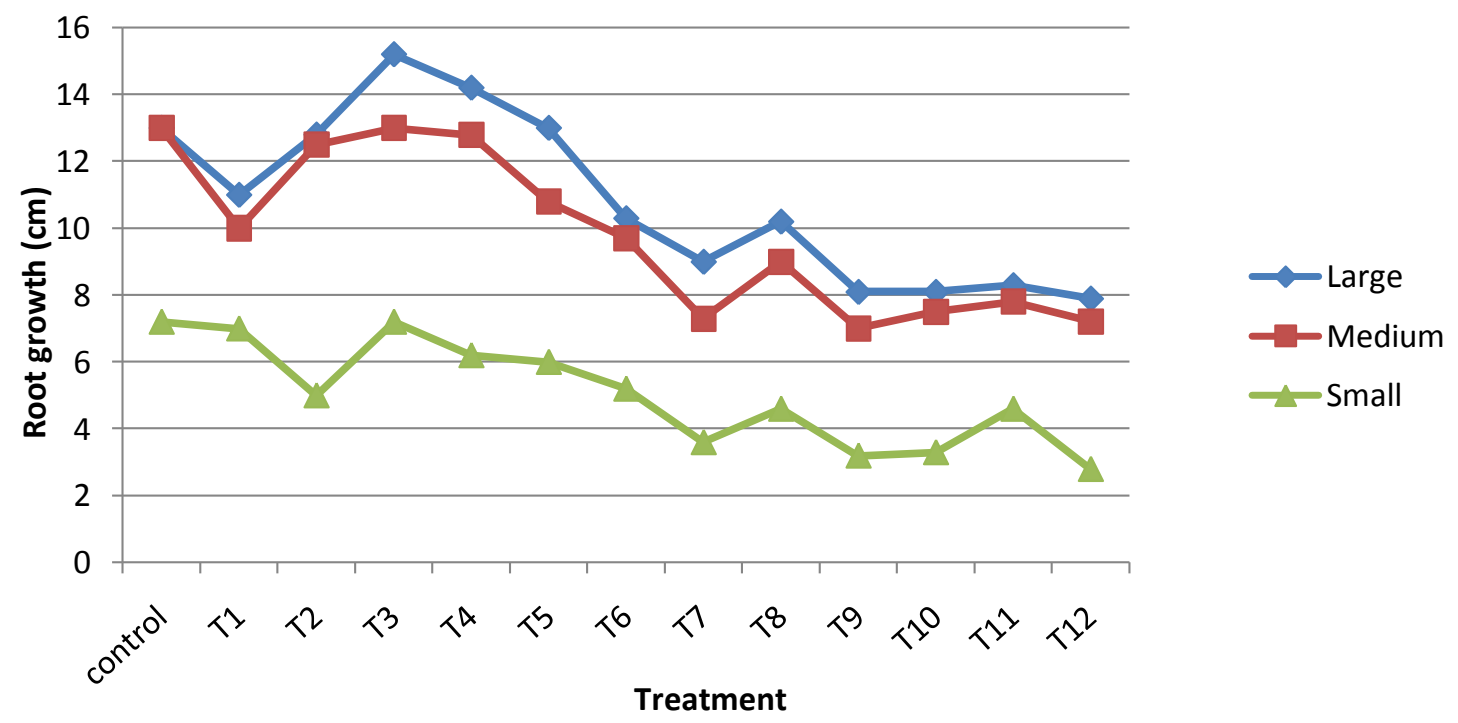




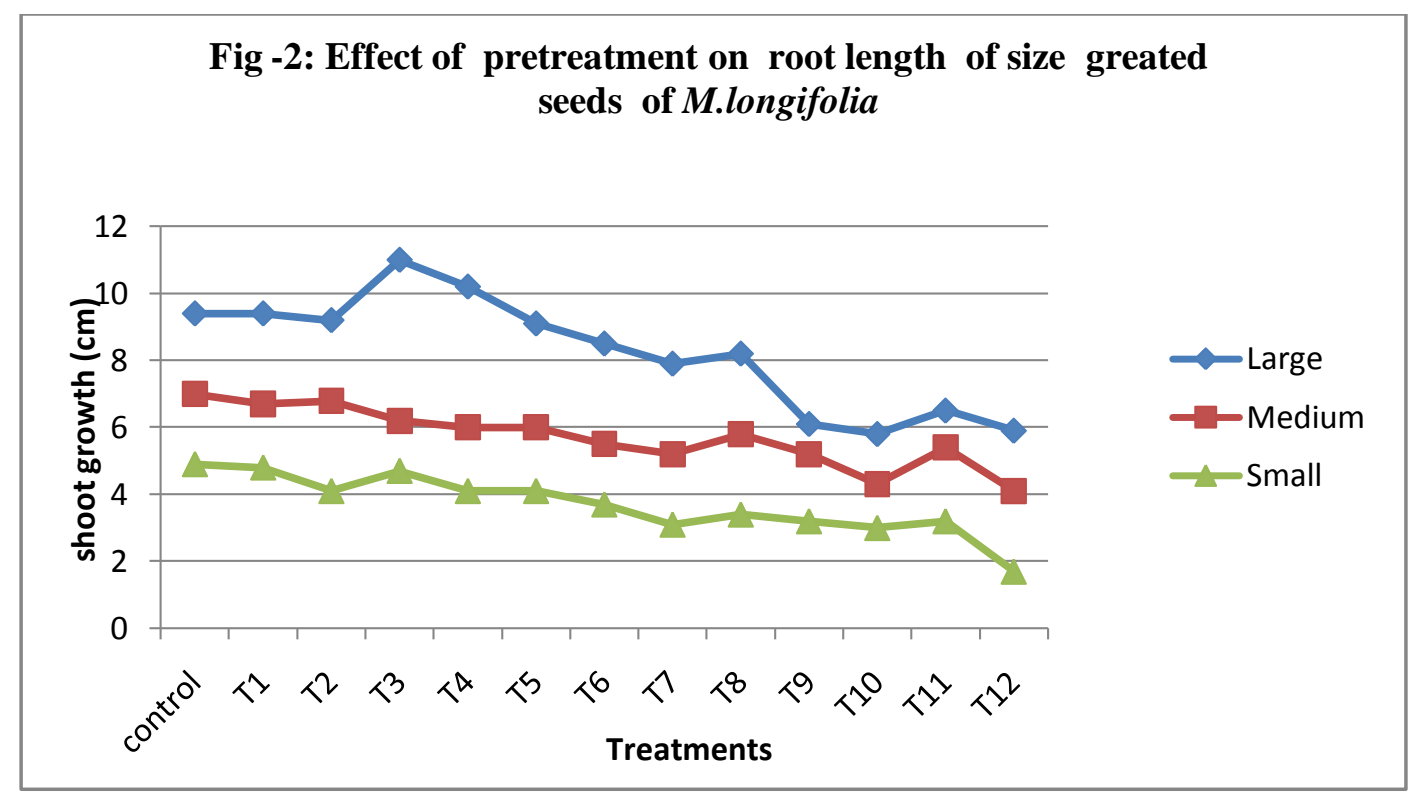

\section{References:-}

1. Awashti Y. C and Mitra C. R. 1967. Madhuca Indica con stituents of fruit pulp and nut shell. Phytochemistry 6:121-125

2. Bewley, J. D. and M.Black 1994 . Seds: Physiology of development and germination, $2^{\text {nd }}$ edn. Plenum press. Newyork.

3. Bewley, J.D. and M. Black, 1982. Physiology and biochemistry of seeds: In relation to germination vol.2 Springer Verlag New York, pp. 375.

4. Chatterjee Asima and and Pakrashi Satyesh Chandra. 2000. The treatise on Indian medicinal plants vol-4 reprint 56-58.

5. Chandra D 2001.Analgesic effect of aqueous and alcoholic extracts of Madhuca longifolia (Koeing). Indian Journal of pharmacology.33:108-111.

6. Hunumantha, M., B.G.Nayak and B.S. Ganiger, 2002. Effect of pre sowing treatments on few growths attributes of Albizia lebbeck (L.)Benth. My Forest, 38(2):139-143.

7. Naidu , C.V. and M.Mastan, 2001. Seed pretreatment methods to improve germination in Pterocarpus santalinus Linn. F. Indian Journal of Forest, 24(3) : 342-343.

8. Saluja M. S., Sangameswaran B, Hura I. S. Sharma A. Guota S. K. and Chaturvedi M. 2011. In vitro cytotoxic activity of leaves of Madhuca longifolia againt Ehrlich Ascites carcinoma(EAC) cell lines, International Journal of Drug discovery and herbal research.1(2: 55-57)

9. Sunita M and P. sarojini,2013 Madhuca Longifolia (Sapotaceae): A review of its traditional uses and nutritional properties. International Journal of Humanities, Soc. Sci. Invent. 2(5):30-36 